\title{
A RUA: UM ACOLHIMENTO FALAZ ÀS CRIANÇAS QUE NELA VIVEM ${ }^{1}$
}

Moneda Oliveira Ribeiro ${ }^{2}$

Ribeiro MO. A rua: um acolhimento falaz às crianças que nela vivem. Rev Latino-am Enfermagem 2003 setembro-outubro; 11(5):622-9.

O artigo enfoca a criança em situação de rua, por meio de relatos de um grupo de crianças em idade escolar que freqüentavam dois refúgios públicos da cidade de São Paulo. Teve o objetivo de captar como as crianças que vivem na rua representam sua realidade. Os dados, coletados por meio de entrevistas, foram sistematizados e analisados segundo 0 método de Análise de Conteúdo. As categorias temáticas destacadas do discurso transcrito foram agrupadas em experiências significativas para as crianças, entre as quais "a rua". A síntese das categorias analisadas evidenciou que a violência permeia a vida delas, resultando em experiências que restringem seu pleno desenvolvimento. A rua representa um refúgio para as crianças que procedem de uma família carente de recursos e para as que têm história de maus-tratos pela família.

DESCRITORES: menores de rua; síndrome da criança maltratada; violência

\section{THE STREET: A DECEITFul SHELTER TO THE CHILDREN LIVING IN IT}

The paper focuses on the child in a street situation, through the address by a group of school-age children who used to frequent two public São Paulo city shelters. The purpose was to apprehend its representation on its reality. The data, gathered by means of interviews, were organized and analyzed according to the method of the Analysis of Contents. The thematic theories detached from the speech transcript were grouped into meaningful experiences for the children, among which "the street". The synthesis of the analyzed categories showed clearly that violence permeates the lives of children of/in the street, resulting in experiences that restrict their full development. The street represents a refuge to the child coming from a needy family and also to the one who has a history of abuse from its family.

DESCRIPTORS: homeless youth; battered child syndrome; violence

\section{LA CALLE: UN ACOGIMIENTO MENTIROSO PARA LOS NIÑOS QUE VIVEN EN ELLA}

El artículo enfoca relatos de niños (en edad escolar) que viven en las calles de la ciudad de São Paulo y frecuentan dos refugios públicos. El objetivo del trabajo fue captar como los niños de la calle representan su realidad. Los datos, recolectados por medio de entrevistas, fueron organizados y analizados según el método de Análisis de Contenido. Las categorías temáticas destacadas de las entrevistas transcriptas fueron conjuntadas en experiencias significativas para los niños, entre ellas, "la calle". La síntesis de las categorías analizadas evidenció que la violencia atraviesa la vida de esos niños, trayendo como resultado experiencias que restringen su pleno desarrollo. La calle representa un refugio para el niño que proviene de una familia carente de recursos y que tiene una historia de malos tratos por parte de la familia.

DESCRIPTORES: jóvenes sin hogar; síndrome del niño maltratado; violencia

\footnotetext{
${ }^{1}$ Desmembramento da tese "A criança de/na rua em idade escolar: um olhar sobre sua trajetória de vida" apresentada à Escola de Enfermagem da Universidade de São Paulo; ${ }^{2}$ Enfermeira, Professor Doutor da Escola de Enfermagem da Universidade de São Paulo, e-mail: moneda@usp.br
} 
INTRODUÇÃO

$\boldsymbol{A}$ rua é um espaço que estimula, mas também restringe o desenvolvimento da criança. Oferece muita liberdade, mas também muitas renúncias. Possibilita ampliar as relações de amizade, mas também revela a perversidade de seus pares. Ela dá a impressão de que tudo é acessível, mas muito pouco pode ser apreendido. Ela acolhe qualquer um, mas torna todos muito vulneráveis. A rua é assim, tal como uma "sereia", seduz e atraiçoa.

A rua, do modo como hoje está constituída nas grandes cidades, não é um espaço que propicia um desenvolvimento sadio à criança. Nela, há muitos perigos. Se, por um lado, a criança aprende a ser "maliciosa e esperta" para se defender das mais distintas formas de violência, por outro, aprende que ninguém é digno de seu afeto, nem ela mesma. A vivência na rua leva a criança a ver o mundo acinzentado. A criança sonha acordada, não vive o mundo do faz-de-conta. Desde a tenra idade, descobre que Papai Noel não existe. Ela tem pressa de tornar-se adulta porque sabe que é o requisito necessário para adquirir habilidades que a tornarão independente. Ela perde o que há de mais nobre na infância: a fantasia.

A criança em situação de rua não difere, em essência, da criança que vive com sua família e freqüenta a escola. No que se refere às características universais próprias de cada estágio de seu desenvolvimento, é tão criança como outra qualquer. No entanto, ela tem experiências muito peculiares que a tornam diferente das demais. Por viver em condições adversas ao seu pleno desenvolvimento, passa a ser constituída como "grupo de risco". Isso significa que ela integra uma parcela da população que é carente das condições básicas (de saúde, educação, moradia e alimentação) para se desenvolver.

Uma vez caracterizada a situação de risco, há a necessidade de se elaborarem ações de saúde mais dirigidas a esse grupo específico. Mas a participação dos profissionais de saúde em Programas de instituições públicas ou organizações não governamentais é restrita. Quando eles participam, o trabalho desenvolvido é voluntário e, portanto, limitado a ações muito específicas. Considerando a formação curricular, um enfermeiro poderia ser muito atuante nesses Programas. Mas, ao contrário do esperado, pouco conhece sobre a demanda de necessidades desse grupo específico e sobre as ações de saúde que poderiam ser empreendidas.

Contudo, mesmo isoladamente, alguns profissionais empenham-se em propor intervenções de enfermagem que possam ajudar a criança em situação de rua. Assim, embora ainda restrito no âmbito da enfermagem, esse tema vem ganhando expressão. Em um trabalho dirigido a adolescentes em situação de rua é descrita uma forma de cuidar, que pode ser realizada por enfermeiros, numa perspectiva de apoio à auto-estima $\mathrm{e}$ de resgate da cidadania por meio da Terapêutica de Florais de $\operatorname{Bach}^{(1)}$

A temática da cidadania tem se tornado um enfoque crescente na assistência de enfermagem ${ }^{(2)}$. A violência urbana tem acometido, principalmente, os adolescente, vindo a ser integrada como uma intervenção em âmbito da saúde pública, onde o enfermeiro se encontra numa condição privilegiada de exercer um papel de referência nas situações vividas pelos adolescentes ${ }^{(3)}$.

O presente trabalho teve o intuito de contribuir com essa nova tendência na enfermagem, buscando conhecer as peculiaridades da criança que perambula pelas ruas da cidade de São Paulo (tão presente no cotidiano, mas pouco acessível aos profissionais de saúde). Para tanto, nele é apresentada parte de um estudo sobre a trajetória de vida de um grupo de crianças em idade escolar que vive na ou da rua. O objetivo consistiu em identificar como um grupo de crianças de rua retrata sua trajetória de vida, com o propósito oferecer subsídios ao profissional enfermeiro para que possa consolidar propostas alternativas de assistência e de ensino com vistas à promoção do desenvolvimento dessa categoria de crianças, uma vez que a atenção a elas transcende o âmbito da assistência à saúde, trata-se, inclusive, de um exercício da cidadania.

\section{METODOLOGIA}

A "rua" consistiu em uma das categorias advindas do processo de sistematização do texto discursivo apreendido por meio de entrevistas com crianças que usavam a rua como meio de sobrevivência e espaço para seu desenvolvimento.

Para atingir o objetivo proposto, elegeram-se crianças em idade escolar (de 7 a 12 anos) que viviam na cidade de São Paulo (SP-Brasil). Considerou-se que a criança nessa faixa etária tem capacidade para comunicarse por meio da linguagem e, dessa forma pode emitir sua representação de mundo e a compreensão que tem da 
realidade que a cerca. Por essa razão, a entrevista semiestruturada foi a estratégia escolhida para obter os dados que permitissem identificar sua representação em relação a si mesma, a sua família, ao meio onde vive e aos demais enfoques por ela revelados.

A coleta de dados

Os dados foram coletados por meio de entrevistas realizadas individualmente com catorze crianças que freqüentaram dois refúgios públicos da cidade de São Paulo: um abrigo vinculado a uma instituição estadual e um albergue da prefeitura, administrado por uma entidade não-governamental. A delimitação do número de participantes não foi previamente estabelecida. Restringiuse o número de entrevistas em função da disponibilidade das crianças durante a permanência do pesquisador no campo e segundo um "critério de saturação"(4), cujo número de entrevistas de uma pesquisa qualitativa é considerado suficiente quando os últimos informantes fornecem dados muito semelhantes aos anteriores. Assim, nos dias agendados para a coleta dos dados, do total de quinze crianças abordadas, uma recusou-se a participar.

A autorização para realizar as entrevistas com as crianças ocorreu em duas instâncias: junto aos responsáveis pelos refúgios e por meio das próprias crianças. Teve-se o cuidado de explicar o objetivo e o caráter sigiloso da pesquisa, bem como o procedimento das entrevistas. As crianças e seu responsável foram devidamente esclarecidos sobre a utilização de sua informação. Assim, manifestaram o consentimento informado, conforme preconizado pelos princípios éticos das pesquisas com seres humanos, previstos na resolução no 196 , de 10 de outubro de 1996, do Conselho Nacional de Saúde.

As entrevistas iniciavam com uma pergunta aberta como "conte-me sobre sua experiência na rua" ou "como você se sente estando na rua" e transcorriam com intervenções da pesquisadora (no caso, a autora), com o intuito de estimular as crianças a continuarem falando. Assim, as entrevistas evoluíam com um diálogo espontâneo. Em geral, as crianças eram prolixas, somente algumas necessitavam ser estimuladas com perguntas que surgiam do próprio contexto enfocado para esclarecer pontos obscuros ou obter mais informações a respeito do tema em vigor. Além disso, a pesquisadora (identificada com a letra "P", nos diálogos transcritos) teve a preocupação de usar uma linguagem simples e concreta, compatível com a fase do desenvolvimento das crianças, evitando o uso de conceitos além da compreensão delas.

Embora as entrevistas tivessem um propósito bem definido, o pesquisador conduziu as entrevistas segundo alguns princípios da abordagem "não-diretiva"(5), sobretudo no que se refere às atitudes de compreensão, aceitação e interesse pelas crianças, de modo autêntico e congruente, para que elas não se sentissem ameaçadas ou julgadas.

A sistematização dos dados

O instrumento principal utilizado para se obter a visão de mundo do indivíduo é seu discurso. Este, expresso por meio da linguagem, possibilita sua decomposição e reconstrução, tornando possível a compreensão do conteúdo da mensagem. "A linguagem, como produto de uma coletividade, reproduz, por meio dos significados das palavras articuladas em frases, os conhecimentos (...) e os valores associados a práticas sociais que se cristalizaram; ou seja, a linguagem reproduz uma visão de mundo, produto das relações que se desenvolveram a partir do trabalho produtivo, para a sobrevivência do grupo social"(6). Por meio da linguagem, "a criança representa o mundo que a cerca e que influenciará seu pensamento e suas ações no seu processo de desenvolvimento e de hominização"(6).

A linguagem revela o pensamento, por isso, o registro do discurso das crianças, proveniente das entrevistas, foi o meio pelo qual se obteve a versão delas em relação ao objetivo do estudo. Assim, os dados foram registrados por meio de gravação e transcritos na íntegra.

A sistematização do texto transcrito foi realizada conforme as principais normas de validade da "análise temática" ${ }^{, 7)}$, uma das técnicas de Análise de Conteúdo ${ }^{(8)}$ que, por sua vez, consiste em "um conjunto de técnicas de análise das comunicações, visando obter, por procedimentos sistemáticos e objetivos de descrição do conteúdo das mensagens, indicadores (quantitativos ou não) que permitam a inferência de conhecimentos relativos às condições de produção/recepção (variáveis inferidas) destas mensagens"(8).

Os dados foram sistematizados tendo em vista os seguintes passos da análise temática: "exaustividade" (contemplaram-se todos aspectos do roteiro); "representatividade" (considerou-se a representação dos 
temas no universo pretendido); "homogeneidade" (respeitaram-se os critérios de escolha por temas); "pertinência" (levaram-se em conta os registros coerentes com o objetivo do trabalho) $)^{(7)}$. A operação de codificação sucedeu, determinando-se a "unidade de registro/ significação" (palavra-chave ou frase), a "unidade de contexto" (a delimitação do contexto de compreensão da unidade de registro), os "recortes" (contextos mais relevantes), a "categorização" (classificação e a agregação das unidades de registros, relacionando-as com as respectivas unidades de contexto dos temas predominantes) e os "conceitos teóricos" mais gerais que orientaram a análise ${ }^{(7)}$. Assim, uma das unidades temáticas que surgiu do processo de decomposição e reconstrução dos discursos das crianças entrevistadas originou a categoria "rua".

A análise dos dados

As unidades temáticas, organizadas sistematicamente, tornaram aparente o que estava implícito no discurso. Essa estratégia, de tornar explícito o implícito, possibilitou reconhecer valores de referência, padrões de comportamentos e julgamentos relevantes para a proposta do estudo. Assim, os resultados foram apresentados destacando-se as informações obtidas conforme a relevância dos temas.

A análise dos dados procedeu-se em função dos temas emergentes que representaram a reconstrução das dificuldades enfrentadas pelas crianças em seu processo de desenvolvimento. A interpretação dos dados foi fundamentada, baseando-se em referenciais teóricos de autores que realizaram estudos relacionados ao desenvolvimento infantil, numa abordagem humanista e histórica. Ou seja, os argumentos inferidos foram pautados em autores que consideram a determinação social nas concepções que o indivíduo constrói sobre si mesmo e sobre o mundo, vindo a influenciar suas condutas nas relações pessoais e sociais.

\section{RESULTADOS}

As crianças apresentaram duas razões principais que as levaram a fugir de casa e recorrerem à rua: por serem vítimas de maus-tratos em sua casa ou por necessitarem suprir carências decorrentes de sua condição socioeconômica. Elas representavam a rua de modo ambíguo, ora como uma experiência prejudicial a si próprias, ora como ponto de acolhimento, pois recorriam a ela como alternativa para livrarem-se dos ambientes hostis de onde eram provenientes. Contudo, reconheciam que a rua não é um lugar amistoso. Eram conscientes de que sua permanência na rua estimulava-as a fazer "coisas ruins". Elas também se queixavam do tratamento que recebiam dos adultos e de seus adversários. As rivalidades entre os grupos de crianças faziam parte de seu cotidiano, por isso andavam sempre acompanhadas por seus pares. Algumas crianças, antes de fugirem de casa, já tinham a rua como um espaço usual no seu dia-a-dia; nesses casos, as crianças não se apresentavam tão críticas em relação à vida na rua.

Para integrarem-se nesse meio e pertencerem a um grupo, as crianças precisavam fazer coisas em comum: "cheirar cola", pedir esmola e cometer pequenos furtos. Não havia como fugir dessa rotina, fosse para sobreviverem à fome ou para conseguir a simpatia dos companheiros, as crianças que ficavam na rua eram pressionadas a agirem conforme o padrão. Por outro lado, a rua também tinha seus atrativos, sobretudo a liberdade de fazerem o que desejavam, salvo as limitações de suas próprias carências. Mas, ainda assim, segundo as representações apreendidas nos discursos, o saldo era negativo. As crianças classificavam a rua como uma experiência ruim. Freqüentemente, conseguiam descrever o que era ruim na rua, mas nem sempre sabiam dizer o que era bom.

Você lembra de uma coisa boa que aconteceu com você?
M. Não sei.
E uma coisa ruim que você nunca esqueceu?
M. Ficar na rua.
P. Você gosta da vida que está levando?
E. Mais ou menos.
P. O que tem de bom e o que tem de ruim?
E. De ruim... eu preciso de roupa, de sapato, preciso de tudo. De mal... preciso parar de cheirar cola, de fumar pedra, de roubar, não ficar na rua. Queria ter uma roupa, ter um trabalho, ter um sossego, ter uma casa, ter uma mulher.

$P$. E o que é bom para você, na vida que você tem?

E. Não sei.

P. O que você gostaria de contar pra mim dessa experiência de estar na rua?

K. Eu gosto de ficar na rua. Estou tentando parar de fazer 
coisa ruim, cheirar cola, fumar cigarro, maconha.

$P$. O que é bom e o que é ruim na rua.?

K. Na rua, nós come coisa mais gostosa.

P. O que é difícil na rua?

T. Pra mim é por causa que os polícia bate em nós. $A$ gente pede dinheiro pras pessoas e elas não dá. A gente pede pra pagar uma coisa pra nós comer, eles não pagam. Então, na rua, a gente tem uma parte boa, mas uma parte ruim. A parte boa é do carinho, do amor e do carinho que se tem das pessoas (refere-se aos amigos). E a parte ruim é que, durante o dia, a gente fica com fome, muita fome. À noite, a gente entra (no albergue), toma banho e come, mas, durante o dia, a gente fica com fome, não tem onde tomar banho. Se não fosse aqui a gente ia ficar sujo, imundo. Tem gente que fala que a gente fica na rua porque quer. Eles não sabem o motivo que a gente tem pra tá na rua. Não é porque eu quero. Eu queria morar com a minha mãe (tia guardiã). Mas ela deu eu pro meu pai, com 10 anos. Aí eu fugi.

O dia-a-dia

Quando as coisas transcorriam normalmente, as atividades das crianças consistiam em brincar, cheirar cola, perambular, pedir esmola e participar das atividades organizadas pelas instituições que acolhiam as crianças em situação de rua. As crianças chegavam a percorrer longas distâncias em um único dia, do centro para a periferia da cidade e vice-versa.

P. Queria que você me contasse sua experiência na rua.

G. Eu tô aqui desde que abriu o albergue. Uso droga, cheiro cola, jogo bola, capoeira, fico com meu irmão. Todo dia nós vai para prainha, no Guarapiranga.

P. Conte-me sua experiência de vida na rua.

E. Eu cheiro cola, roubo, uma par de coisa, fumo maconha, menos farinha que eu não cheiro, e menos cocaína, essas coisas eu não uso. Acontece uma par de coisa, os moleques na rua me batem, tem vez que eu vou pro $C C C A^{*}$ ou eu fico aqui no Bar, arrumo dinheiro aqui.

$P$. O que você faz na rua?

E. Na rua, fico cheirando cola, roubando. Roubando não, eu não roubo, roubo de vez em quando. Fumando pedra não, eu não fumo pedra não, de vez em quando eu fumo. Mas só que eu fico cheirando cola aqui, de vez em quando eu vou lá no CCCA, na Casa Aberta, e no terminal Santo Amaro, que tem um abrigo lá. Aí, de noite, eu venho pra cá, pra dormir, depois eu volto de novo lá.
Os conflitos

Os conflitos vivenciados pelas crianças ocorriam em diversas instâncias: com a polícia, com os adultos habitantes da rua, com o cidadão comum e com seus pares. As crianças conviviam com a hostilidade diariamente, a sensação de desamparo era constante porque não conseguiam desvencilhar-se de seu maior inimigo: a violência.

P. Faz tempo que você está na rua?

K. Desde 1994 que eu estou na rua. Eu estava em Susano (interior do estado de São Paulo). O moleque me chamou pra vir pro Brás (centro da cidade de São Paulo). Aí eu vim com meu irmãozinho. Eu fiquei mor (muito) assustado. Aí eu e meu irmão voltamo pra Susano, pra nossa casa.

P. Você ficou assustado com o quê?

K. Com a polícia, antes eu tinha maior medo de polícia.

(...) Mas agora não tenho mais medo não.

P. Quando você estava na rua, como você era tratada lá? Quem cuidava de você?

J. Eu tinha minhas amigas, né. Mas era muita briga. (...)

P. Quem te protegia?

J. Só Deus. Eu ficava pensando em Deus e nada acontecia comigo.

\section{Os grupos}

A inserção das crianças nos grupos de amigos tinha o propósito de se protegerem, eram essenciais para sua sobrevivência na rua. A solidariedade era um lema. Mas, em contrapartida, essa estreita convivência também era motivo de muitas desavenças. Ainda assim, querendo ou não, elas precisavam pertencer a algum grupo para se manterem protegidas.

P. A rua não é perigosa?

T. Pra mim não, porque eu ando com uma par de menina e de menino. É uma turma de menina e meninos, nós anda tudo junto, a maioria. Se alguém vem mexer com nós, eles defendem nós. Mas não vai assim na violência, nós conversa. Mas se um menino vier agredir, nós agride também.

P. Você já brigou?

T. Muitas vezes. Sabe por quê? Eu não gosto que mexe com minhas amigas. A gente é assim... se a gente tem um dinheiro... se eu ganho um dinheiro e tá só eu, eu não gasto só comigo. Eu gasto com eles também, porque, quando eles têm, eles gastam

* CCCA (Centro Comunitário da Criança e do Adolescente): Entidade filantrópica com fins educativos 
comigo. Se tá quatro pessoas e tem dez reais, é dois e cinqüenta pra cada um. Se tá só eu e a outra pessoa, é cinco pra cada. A gente compra coisa pra nós comer. O resto, a gente compra roupa, sandalha, creme de cabelo, maquiagem. Não é porque a gente mora na rua que a gente vai andar mal arrumado. Porque as pessoas ficam olhando pra nossa cara.

H. Eu sempre andei sozinho, nunca andei com gangue, nunca andei com grande, nunca andei com maior que eu. Não gosto de andar com muito moleque, eu ando só com meu colega, só nós dois. Porque é muita zoeira, começa aquela confusão, sai briga, um pode se machucar, pode se comprometer na vida, daí pode matar sem obrigação. E não pode ser assim com muita violência. (...) Eu não sou de confusão, tia, mas quem arranjar comigo, também leva. Eu não tô na rua pra mim ser saco de pancada, pra mim apanhar desses moleques. Eu tô na rua porque minha vida tá ruim.

\section{O desconforto}

O que parece incomodar mais as crianças, além do tratamento hostil que recebiam na rua, era o desconforto devido à fome, ao frio e à falta de higiene. Esse mal-estar era tão perturbador que havia crianças que chegavam a hesitar se retornavam ou não para casa, apesar do ambiente hostil com o qual vinham convivendo. Mas, no "frigir do ovos", acabavam decidindo-se pela sua manutenção na rua ou nos abrigos.

\section{$P$. Como é ficar na rua?}

L. Não é bom, não. Você passa um montão de frio. Tem gente que maltrata nóis.

P. O que acontece com as crianças quando elas estão na rua, como se cuidam?

J. Na rua é muito difícil a gente se cuidar. A gente tá sujo. Onde nós ia, num lugar, nós senta, deita. Mas onde eu tava tinha um lugarzinho que a gente tomava banho, mas é frio, né. Uma casinha. Mas roupa, a gente se arrumava. Às vezes a gente colocava a mesma roupa. Às vezes não. Às vezes a gente ficava suja. Tem bastante gente que fica com medo de dormir na rua. Tem medo de bater nelas. Tem medo de morrer.

P. Você dormia no chão?

J. No chão, só com uma coberta. Era ruim pra dormir no chão. Até pensava, preferia ficar na minha casa do que ficar na rua. Aí fui me acostumando. Aí depois fiquei pensando pra que serve isso e comecei a ir pro SOS*. Aí acostumei, mesmo que eu voltar pra casa, não vou poder ficar lá, não vou agüentar. Minha mãe (madrasta) vai bater muito, porque, dessa vez, eu fiquei fora mais que os outros tempos.

O tempo

Na rua, as crianças tinham a noção do tempo relativamente prejudicada. O uso de drogas era a principal razão para essa desorientação. O fato de não freqüentarem a escola, nem desenvolverem uma atividade regular, também dificultava sua orientação no tempo, uma vez que a ociosidade torna indiferente se determinado dia é segunda-feira, sábado ou feriado.

P. Faz tempo que você tá na rua?

W. Faz.

P. Desde quando?

W. Desde 99.

P. Mas você não lembra que mês? Porque nós ainda estamos em 99
W. Desde seis anos. Eu tava na rua.
$P$. E agora você tá com doze.
W. É.
$P$. Há quanto tempo você tá na rua?
E. Deixa eu ver quantos mês... faz uns cinco, dez meses.

\section{DISCUSSÃO}

Os relatos apresentados pelas crianças rompem com a idéia dos que acreditam que elas estão na rua por vontade própria. Na realidade, para elas, a rua é uma alternativa em função de uma situação circunstancial e de suas condições de vida. Mesmo quando as crianças buscam a rua para ter liberdade e diversão, essa escolha resulta das restritas possibilidades que encontram para integrarem-se ou manterem-se em atividades escolares ou desportivas. Além disso, a liberdade que a rua possibilita é relativa.

"O fato de uma pessoa estar sem atividade, sem fazer nada, não significa obrigatoriamente que essa pessoa seja livre. (....) A liberdade está relacionada com a sensação de satisfação, de estar fazendo aquilo que tinha muita vontade de fazer. (....) Liberdade existe apenas antes de uma escolha. Uma vez feita a escolha, ela envolve responsabilidade e o conseqüente prazer em desfrutar essa escolha"(9)

As crianças entrevistadas deixavam evidente suas

* SOS Criança: Entidade pública que acolhe crianças em situação de risco pessoal e social 
poucas possibilidades de escolha, o que as tornava limitadas em satisfazerem suas vontades ou realizações. Ainda assim, optavam pela rua "porque ela representa, num determinado momento, tudo o que nunca tiveram, não só a liberdade mas também o acesso quase que direto aos benefícios da cidade" ${ }^{\text {(10) }}$.

Mas "de ilusão também se vive". A rua dá a impressão de que tudo é acessível, embora muito pouco possa ser apreendido pelas crianças, dada sua condição de existência. Entretanto, as conseqüências de permanecerem na rua não tardam a vir. As crianças tornam-se muito vulneráveis. Na "busca de estar satisfazendo uma curiosidade, uma fantasia ou estar tentando garantir algum dinheiro, começa (....) o envolvimento com o lado ilícito da rua, fazendo uso de drogas e participando de pequenos furtos. Assim, a rua começa a oferecer aos meninos e meninas seu outro lado, onde existe o preconceito da cidade, as perseguições de adultos delinqüentes, as pressões da polícia, destruindo o sonho e a ilusão de que a rua é um espaço sem normas, regras e de liberdade plena"(10).

Ainda assim, preferiam permanecer na rua porque revelavam sofrerem maior privação no convívio com a família ou nos abrigos. Apesar de viverem em desconforto, sem poderem atender suas necessidades básicas e ainda viverem um cotidiano conflituoso em suas interações com seus pares, a polícia e o cidadão comum, a rua oferece aos meninos e meninas de rua "elementos atrativos importantes, principalmente a droga que ajuda a minimizar a frustração, a angústia, o medo, tornando-os mais capazes e proporcionando a coragem necessária, mesmo que fictícia, para enfrentar os desafios que a vida na rua impõe" ${ }^{\text {"(10). }}$.

Mas a vida na rua impõe às crianças um custo muito alto: sua saúde. Isso se tornou evidente em um estudo comparativo entre três grupos distintos de crianças pobres, em idade escolar, onde foi demostrado que há diferenças significativas entre as crianças que estavam vivendo na rua ("homeless"), as que já viveram essa experiência ("previously homeless") e as que nunca vivenciaram a situação de rua ("never homeless"). O estudo consistiu em avaliar a saúde física, a saúde mental e os hábitos quanto aos cuidados de saúde de cada grupo, por meio de testes psicométricos, escalas de ansiedade e entrevistas com as mães das crianças ${ }^{(11)}$.

Em relação aos problemas físicos e aos hábitos de saúde, surgiram mais semelhanças que diferenças entre os grupos. Entretanto, em relação à propensão para a depressão, os "homeless" e os "previously homeless" apresentaram diferença significativa, quando comparados aos "never homeless". E, em relação ao nível de ansiedade, os "homeless" mostraram níveis significativamente mais altos que os "previously homeless" e os "never homeless". Concluiu-se que as crianças dos três grupos constituem uma população de risco, têm muitas necessidades de saúde insatisfeitas em vários aspectos, por isso são propensas a problemas de saúde tanto físicos como mentais. Entretanto, as crianças que estão ou já estiveram em situação de rua apresentam maior risco para a depressão e a ansiedade que as crianças pobres que nunca vivenciaram essa experiência ${ }^{(11)}$.

As crianças, sujeitos do presente estudo, demonstraram parecer cientes dos riscos a que estão expostas, mas davam a impressão de que permaneciam na rua como se estivessem esperando o tempo passar até tornarem-se adultas. Elas sabiam que esse era o requisito para a conquista de maior respeito, para adquirir capacidades e obter oportunidades de trabalho e, assim, ganharem sua independência. O tempo, entretanto, era relativo e subjetivo. Para elas, uma criança com dois ou três anos a mais que sua idade, já é suficientemente grande, quase um adulto. Elas viviam um tempo e espaço próprio, à margem do convencional. Tanto o futuro como o passado, eram referidos em relação aos fatos vividos e aos sonhos aspirados.

Essa referência pessoal de tempo é comum entre os habitantes da rua. Estes podem dar duas respostas diferentes à mesma pergunta quando interrogados em tempo cronológico distinto. O tempo é referido em função de fatos ocorridos em seu cotidiano.

Por isso a rua funciona como uma instituição fechada, ainda que num espaço aberto. "Alguém vai para a rua quando já perdeu todas as referências anteriores. A escola, o trabalho, a família. Aquilo que estava depositado nestas instituições é colocado agora de forma maciça na rua. É ali que vai aprender a sobreviver e tentar refazer seus vínculos afetivos. Tudo em um só lugar, em um só momento (....)"(12).

Nesses termos, a rua constitui um "ecossistema", uma estrutura à margem da sociedade. As pessoas que nela vivem, ou sobrevivem, representam esse mundo singular. As crianças entrevistadas, quando expressavam sua realidade subjetiva, revelavam realidades similares a 
seus pares, uma vez que estes também estão sujeitos aos mesmos determinantes sociais. Assim sendo, cada criança em situação de rua é porta-voz de seu grupo e da categoria que representa, ainda que não seja consciente de estar revelando algo comum às demais crianças que vivem as mesmas condições de existência.

\section{CONSIDERAÇÕES FINAIS}

A criança em situação de rua não só está sujeita à violência, física ou psicológica, como também tem seus direitos violados. No Estatuto da Criança e do Adolescente (Lei № 8.069, de 13/07/90), que regulamenta o artigo 227 da Constituição brasileira de 5 de outubro de 1988, está expresso: "É dever da família, da sociedade e do Estado assegurar à criança e ao adolescente, com absoluta prioridade, o direito à vida, à saúde, à alimentação, à educação, ao lazer, à profissionalização, à cultura, à dignidade, ao respeito, à liberdade e à convivência familiar e comunitária, além de colocá-los a salvo de toda forma de negligência, discriminação, exploração, violência crueldade e opressão"(13).

Ao analisar os relatos da crianças, tornou-se evidente que nenhum dos direitos acima referidos foi assegurado a elas. A sociedade, ou seja, as organizações religiosas, os partidos políticos, os empresários, a mídia, os profissionais liberais, as universidades, as comunidades

\section{REFERÊNCIAS BIBLIOGRÁFICAS}

1. Hirata MC. Crescer na adversidade: um toque na autoestima dos adolescentes: a poética das flores. Salvador (BA): Ultragrafh; 1999.

2. Ferreira MA, Lisboa MTL, Almeida Filho AJ, Gosmes MLB. Inserção da saúde do adolescente na formação do enfermeiro: uma questão de cidadania. In: Ramos FRS, Monticelli M, Nitschke RG, organizadoras. Um encontro da enfermagem com o adolescente brasileiro. Brasília (DF): Associação Brasileira de Enfermagem - Projeto Acolher; 2000. p. 68-72.

3. Almeida HD. Violência urbana: adolescente em emergência pública. In: Ramos FRS, Monticelli M, Nitschke RG, organizadoras. Um encontro da enfermagem com 0 adolescente brasileiro. Brasília (DF): Associação Brasileira de Enfermagem - Projeto Acolher; 2000. p. 73-8.

4. Polit DF, Hungler BP. Fundamentos de pesquisa em enfermagem. 3a ed. Porto Alegre (RS): Artes Médicas; 1995. 5. Rudio FV. Orientação não-diretiva na educação, no aconselhamento e na psicoterapia. 8 ${ }^{\mathrm{a}}$ ed. Petrópolis (RJ): Vozes; 1986.

6. Lane STM. Linguagem, pensamento e representações sociais. In: Lane STM; Codo W, organizadores. Psicologia social: o homem em movimento. $2^{a}$ ed. São Paulo (SP): Brasiliense; 1985. p.32-57. de bairro e o cidadão comum deve ter a incumbência de prover condições adequadas ao seu desenvolvimento. Somente com a participação da sociedade é que se conquistam os direitos da criança, por meio de Políticas Sociais e de Saúde, em consonância com as disposições referidas no Estatuto da Criança e do Adolescente. A solução do problema depende, principalmente, da implementação de políticas públicas que têm como foco a reestruturação das condições de vida das famílias em situação de risco.

O profissional de saúde que deseja exercer sua cidadania, comprometendo-se com a defesa pela melhoria da qualidade de vida da criança em situação de rua, pode inserir-se nos programas de reintegração da criança na família de origem ou substituta, nos programas de recuperação de toxicômanos, nos eventos que defendam os direitos da criança, nos projetos de pesquisa, no ensino e nas distintas formas criativas de tentar resgatar um direito essencial: o direito de "ser criança". Atualmente, há a possibilidade de engajamento nos programas de Promoção da Saúde que vêm sendo desenvolvidos pelo Estado, em parceria com os distintos setores da sociedade, entre os quais as universidades.

No campo da enfermagem, alguns trabalhos já estão sendo realizados nessa perspectiva, entre os quais uma proposta de cuidar numa visão científico-espiritual ${ }^{(14)}$ e um trabalho voltado a desenvolver ações integradas para compreender, atuar e acolher o adolescente ${ }^{(15)}$.

7. Minayo MCS. O desafio do conhecimento: pesquisa qualitativa em saúde. $2^{\underline{a}}$ ed. São Paulo (SP): Hucitec/Abrasco; 1993.

8. Bardin L. Análise de conteúdo. Lisboa (Portugal): Edições 70; 1979.

9. Tiba I. Disciplina: o limite na medida certa. São Paulo (SP): Gente; 1996.

10. Medeiros M. Olhando a lua pelo mundo da rua: representações sociais da experiência de vida de meninos em situação de rua. [tese]. Ribeirão Preto (SP): Escola de Enfermagem de Ribeirão Preto/USP; 1998.

11. Menke EM, Wagner JD. A comparative study of homeless, previously homeless, and never homeless school-aged children's health. Compr Pediatr Nurs 1998; 20(3):153-73.

12. Broide J. Subjetivação, subjetividade, contemporaneidade e grandes transformações políticas nas metrópoles. In: Fórum de Debates Mostra City Canibal; 1998. São Paulo; 1998.

13. Fundo Social de Solidariedade do Estado de São Paulo. Direitos da criança e do adolescente. São Paulo: IMESP; 1993. 14. Ramos FRS. Processo de cuidar do adolescente em situação de rua numa perspectiva alternativa. In: Ramos FRS, Monticelli M, Nitschke RG, organizadoras. Um encontro da enfermagem com o adolescente brasileiro. Brasília (DF): Associação Brasileira de Enfermagem: Projeto Acolher; 2000. p. 144-59.

15. Ramos FRS, Pereira SM, Rocha CRM. Cotidiano e adolescência: novas abordagens. In: Ramos FRS, organizadora. Adolescer: compreender, atuar, acolher. Brasília (DF): Associação Brasileira de Enfermagem - Projeto Acolher; 2000. p. 9-32. 